\title{
Variants within the COMP and THBS2 genes are not associated with Achilles tendinopathy in a case-control study of South African and Australian populations
}

Colleen J. Saunders, Lize Van Der Merwe, Jill Cook, Christopher J. Handley, Malcolm Collins and Alison V. September

\begin{abstract}
Cartilage oligomeric matrix protein is a structural protein of the extracellular matrix, while thrombospondin-2 is a matricellular protein involved in cell-matrix interactions. Recent studies have shown that genetic variation is a significant risk factor for Achilles tendinopathy, and the genes encoding cartilage oligomeric matrix protein (COMP) and thrombospondin-2 (THBS2) were identified as good candidate genes for association with Achilles tendinopathy. This study aimed to test the association of sequence variants within these candidate genes with the risk of Achilles tendinopathy in participants from South Africa (SA) and Australia (AUS). Three-hundred and forty (133 SA; 207 AUS) control participants with no history of Achilles tendinopathy and 178 (94 SA; 84 AUS) participants clinically diagnosed with Achilles tendinopathy were genotyped for five single nucleotide polymorphisms within the COMP and THBS2 genes in this case-control study. There was no difference in genotype distributions between control and tendinopathy groups for either the THBS2 variants rs9505888, rs6422747 and rs9283850, or the COMP variants rs730079 and rs28494505 in the SA and AUS populations. As the selection of COMP and THBS2 as candidate genes was hypothesis driven, based on biological function, the possibility that other variants within these genes are associated with Achilles tendinopathy cannot be excluded.
\end{abstract}

\section{Introduction}

The Achilles tendon is exposed to high mechanical forces during exercise and is often a site of overuse injuries in athletes and the general population (de Jonge et al., 2011; Jarvinen et al., 2001). Achilles tendinopathy is a clinical syndrome comprising of swelling in and around the tendon, tenderness to palpation and pain-induced impairment of physical performance (Jarvinen et al., 2001; Maffulli, Khan, \& Puddu, 1998; Rees, Dent, \& Caterson, 2009; Xu \& Murrell, 2008). Achilles tendinopathy encompasses a range of more specific diagnoses, which includes, amongst others, tendinosis, a condition characterised by chronic degeneration of the tendon without histological signs of inflammation.(Jarvinen et al., 1997; Khan, Cook, Kannus, Maffulli, \& Bonar, 2002). The cumulative lifetime incidence of Achilles tendinopathy in former elite athletes has been estimated at $23.9 \%$, and is as high as $52 \%$ in middle and long distance runners (Kujala, Sarna, \& Kaprio, 2005). Although the pathology of Achilles tendinopathy has been well characterised with clearly documented clinical 
and imaging diagnostic criteria (Del Buono, Chan, \& Maffulli, 2013; Jarvinen et al., 1997; Kader, Saxena, Movin, \& Maffulli, 2002), the exact aetiology of the condition remains undefined. Several extrinsic and intrinsic risk factors for developing Achilles tendinopathy have been proposed, including a significant heritable component (Collins \& Raleigh, 2009; Kannus, 1997; Kannus \& Natri, 1997; September, Mokone, Schwellnus, \& Collins, 2006). To date, polymorphisms in several genes coding for structural and associated proteins of the extracellular matrix have been investigated as candidate genes for the risk of developing Achilles tendinopathy. In particular, sequence variants within the COL5A1, TNC, GDF-5, MMP3, CASP8 and COL27A1 genes, as well as the interleukin genes $I L-1 \beta, I L-1 R N$ and $I L-6$, have been shown to influence an individual's susceptibility to Achilles tendinopathy (Mokone et al., 2005; Mokone, Schwellnus, Noakes, \& Collins, 2006; Nell et al., 2012; Posthumus et al., 2010; Raleigh et al., 2009; Saunders et al., 2013; September et al., 2009; September et al., 2011).

In this study we investigated two further candidate genes, THBS2 and COMP, which code for thrombospondin-2 and cartilage oligomeric matrix protein (thrombospondin-5) respectively. All thrombospondins contain a highly conserved signature protein domain at the carboxy terminal and a number of disease associated genetic variants have been mapped to this domain (Carlson, Lawler, \& Mosher, 2008). Thrombospondin-2, in particular, is involved in the healing response in connective tissues and plays a significant role in cell-matrix interactions (Adams \& Lawler, 2004; Bornstein, Agah, \& Kyriakides, 2004; Bornstein, Armstrong, Hankenson, Kyriakides, \& Yang, 2000). Two single nucleotide polymorphisms (SNPs) within the THBS2 gene (chr6q27), rs9283850 (Intron 9) and rs6422747 (Intron 14), have previously been implicated in a haplotype associated with lumbar disc herniation in a Japanese population (Hirose et al., 2008). Cartilage oligomeric matrix protein interacts with type I and type III collagens and plays an important role in matrix assembly and the repair of injured tissues (Hecht, Hayes, Haynes, \& Cole, 2005; Posey, Yang, Veerisetty, Sharan, \& Hecht, 2008; Rosenberg, Olsson, Morgelin, \& Heinegard, 1998; Sodersten, Hultenby, Heinegard, Johnston, \& Ekman, 2013). Genetic variants clustered in the conserved calcium binding domains and carboxy terminal of the cartilage oligomeric matrix protein have been repeatedly associated with skeletal dysplasias (Adams \& Lawler, 2004; Hecht et al., 2005; Ikegawa et al., 1998) and other cartilage disorders including osteoarthritis of the knee (Valdes et al., 2007). The C-allele of the $\operatorname{rs} 730079(-1417 \mathrm{C}>\mathrm{G})$ SNP within the 5'-UTR of the COMP gene (chr19p13.11) was previously associated with osteoarthritis in a Caucasian male population (Valdes et al., 2007), while the rs28494505 (Intron 18) Tag SNP is located within the highly conserved C-terminal domain of the Cartilage oligomeric matrix protein. These observations, together with the biological roles of these proteins, suggest that both COMP and THSB2 are good candidate genes for association with risk of developing Achilles tendinopathy. The aim of this study was, 
therefore, to test the association of sequence variants within the COMP, rs730079 $(C>G)$ and $\operatorname{rs28494505}(A>G)$, and THBS2, rs9283850 $(A>G), \operatorname{rs6422747}(A>G)$ and $\operatorname{rs9505888}(A>G)$, candidate genes with the risk of Achilles tendinopathy in participants from South Africa and Australia.

\section{Methods}

As previously described, 133 South African asymptomatic control participants (SA CON) and 94 South African participants clinically diagnosed with AT (SA TEN), as well as 207 Australian asymptomatic control participants (AUS CON) and 84 Australian participants clinically diagnosed with AT (AUS TEN) were recruited for this study (Mokone et al., 2005; September et al., 2009). In particular, tendinopathy participants were diagnosed with chronic, degenerative tendinosis without signs of inflammation. The presence of gradual progressive pain over the posterior lower leg for more than six months, together with at least one of the following clinical criteria, was used to diagnose chronic Achilles tendinopathy: (i) early morning pain; (ii) early morning stiffness; (iii) history of swelling over the Achilles tendon area; (iv) tenderness to palpation; (v) palpable nodular thickening over the affected Achilles; and/or (vi) a positive shift test during plantar-/dorsi-flexion (Kader et al., 2002; Schepsis, Jones, \& Haas, 2002). The diagnosis of each tendinopathy participant was reviewed by the same clinician in SA and AUS, and was confirmed using soft tissue ultrasound in a sub-group of SA participants and all the AUS participants. Control participants were physically active and asymptomatic with no history of Achilles tendon injury. Individuals with a self-reported history of treatment with either fluoroquinolone antibiotics or local corticosteroid injections, as well as those who had previously suffered, or were currently suffering from any connective tissue disorders or other systemic diseases associated with Achilles tendinopathy were excluded from the study. All participants were of self-reported Caucasian ancestry, gave written informed consent in accordance with the Declaration of Helsinki and completed a questionnaire providing personal particulars and medical history. This study was approved by the Human Research Ethics Committee of the Faculty of Health Sciences, University of Cape Town and the Human Ethics Committee of La Trobe and Monash Universities, Melbourne, Australia.

The three THBS2 SNPs rs9283850 (A>G), rs6422747 $(A>G)$ and rs9505888 $(\mathrm{A}>\mathrm{G})$ and the two COMP SNPs, rs730079 $(-1417 \mathrm{C}>\mathrm{G})$ and rs28494505 (A>G), were selected based on their linkage, heterozygosity score ( $>35 \%)$, minor allele frequency $(>20 \%)$ and previous association with other clinical phenotypes (Figures 1 and 2) (Hirose et al., 2008; Valdes et al., 2007). The rs9505888 SNP was selected based on its linkage to rs6422747. In addition, all three THBS2 SNPs are identified as Tag SNPs (http://gvs.gs.washington. edu/GVS137) and therefore provide moderate coverage of this $38.3 \mathrm{~kb}$ gene. The rs28494505 variant was selected based on its location within the highly conserved Cterminal domain of the cartilage oligomeric matrix protein and itsidentification as a Tag SNP. 


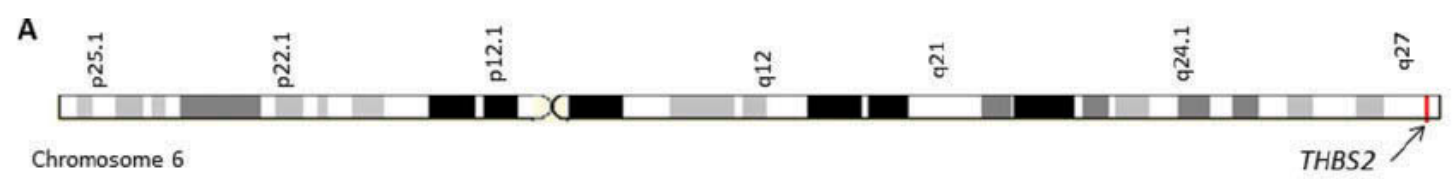

B

169615875 THBS2 $(38,27 \mathrm{~kb})$ 169654139
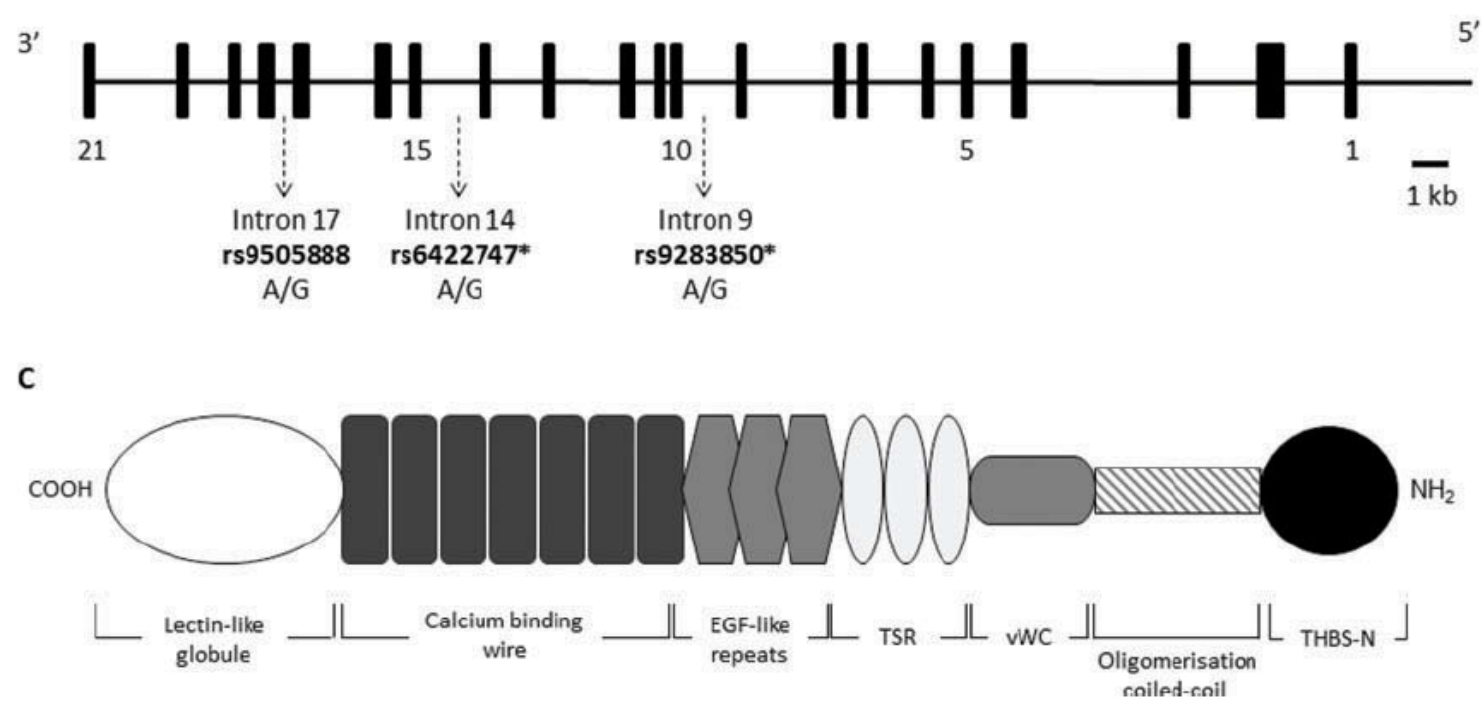

Figure 1. (A) Chromosomal location of the THBS2 gene. (B) Exonic structure of THBS2 *Significant haplotype association with lumbar disc herniation (Hirose et al., 2008) Variants in bold are included in the present study. (C) Thrombospondin-2 protein domain architecture. EGF: Epidermal growth factor; TSR: Properdin-like thrombospondin repeats; vWC: von Willebrand factor type C domain; THBS-N: Thrombospondin N-terminal domain. (Compiled from www.ensembl.org and Carlson et al., 2008.)

DNA for all South African (227) and Australian (291) participants was isolated from venous blood as described by Lahiri and Nurnberger (1991) and modified by Mokone et al. (2005). Variants rs9505888, rs6422747 and rs28494505 were genotyped using standard polymerase chain reaction (PCR) and restriction fragment length polymorphism techniques (PCR conditions detailed in supplementary material). PCR reactions were performed on a thermal cycler (Hybaid: PCR Express, Middlesex, UK) with the resulting amplicon incubated with the BstUI, MfeI and MspI nucleases respectively. Restriction fragments were resolved, together with a 10obp size standard, by $6 \%$ polyacrylamide gel electrophoresis and visualised under UV light after staining with SYBR Gold nucleic acid gel stain (Invitrogen). Variants rs9283850 and rs730079, as well as a subset of samples for rs28494505, were genotyped using TaqMan SNP Genotyping Assays (Applied Biosystems) that were amplified and distinguished using the StepOnePlus Real-Time PCR System (Applied Biosystems). For quality control purposes, a number of positive and DNA-free controls were included in all PCR reactions, and a small subset of samples was analysed for repeatability within each variant.

The programming environment $\mathrm{R}$ ( $\mathrm{R}$ Development Core Team, 2010), and $\mathrm{R}$ package, genetics (Warnes, Gorjanc, Leisch, \& others, 2011), was used for all statistical analyses. Age, sex, country grouping and country of birth were considered potential confounders, and so were corrected for in the logistic regression models of genotype and allele association with 
Achilles tendinopathy, as well as in the linear models of the association of genotype and allele frequencies with physical characteristics of the participants.

\section{Results}

Basic characteristics of the study groups were presented previously and are included in (Mokone et al., 2005; September et al., 2009). Tendinopathy participants were significantly heavier than the control participants at the time of recruitment $(\mathrm{P}<0.001)$; however, this difference was much less pronounced after adjusting for country grouping, sex and age $(\mathrm{P}=0.044)$. Genotype and minor allele frequency distributions for each of the polymorphisms, together with Hardy-Weinberg Equilibrium (HWE) p-values, are shown in Table II. The frequency distributions of the SNPs tested in this study were found to differ significantly between the South African and Australian participant groups at the rs28494505 $(\mathrm{P}<0.001)$ and rs6422747 loci $(\mathrm{P}=0.024)$ (Table II).

Table I

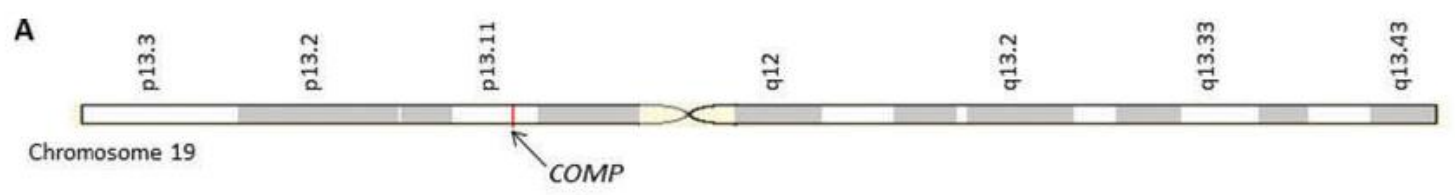

B

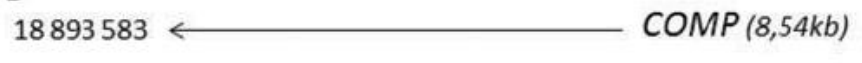

18902123

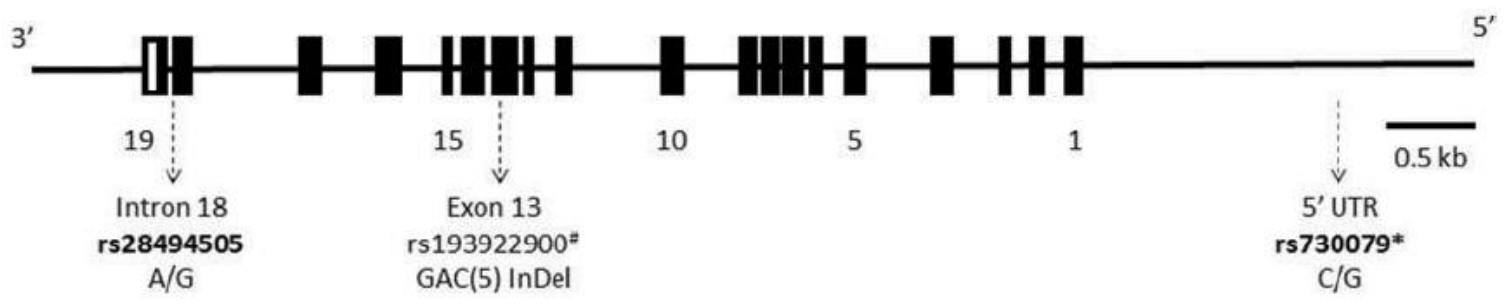

c

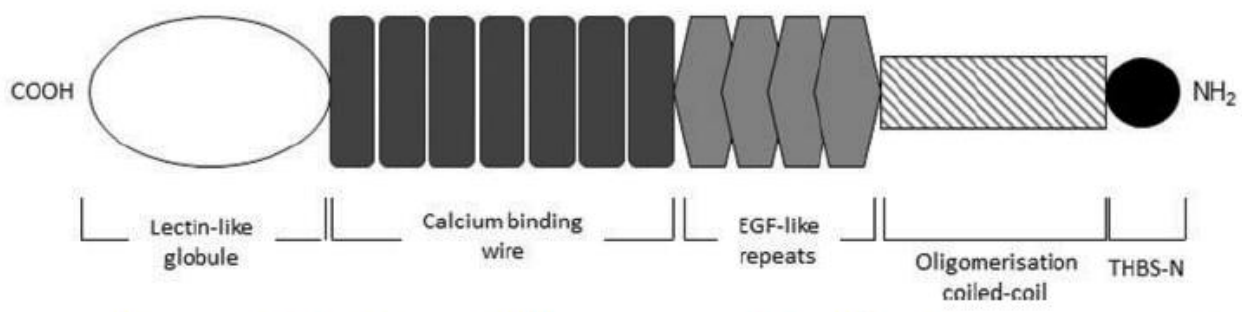

Figure 2. (A) Chromosomal location of the COMP gene. (B) Exonic structure of COMP ${ }^{\star}$ Significant association with osteoarthritis (Valdes et al., 2007) " Significant association with PSACH and MED (Delot, King, Briggs, Wilcox, \& Cohn, 1999) Variants in bold are included in the present study. (C) COMP protein domain architecture. UTR: Untranslated region; EGF: Epidermal growth factor; THBS-N: Thrombospondin N-terminal domain. (Compiled from www.ensembl.org and Carlson et al., 2008.) 
Table I. Descriptive characteristics (mean \pm SD unless specified) of South African (SA) and Australian (AUS) subjects included in the current study.

\begin{tabular}{|c|c|c|c|c|c|c|}
\hline & \multicolumn{2}{|c|}{$\mathrm{CON}$} & \multicolumn{2}{|c|}{ TEN } & \multicolumn{2}{|c|}{$P$-values } \\
\hline & AUS $(n=207)$ & $\mathrm{SA}(n=133)$ & AUS $(n=84)$ & $\mathrm{SA}(n=94)$ & Country & Group \\
\hline Height $(\mathrm{cm})$ & $171 \pm 9$ & $175 \pm 9$ & $174 \pm 10$ & $176 \pm 9$ & $<0.001$ & 0.005 \\
\hline Weight $(\mathrm{kg})$ & $73 \pm 14$ & $71 \pm 12$ & $80 \pm 14$ & $78 \pm 13$ & 0.138 & $<0.001$ \\
\hline $\mathrm{BMI}\left(\mathrm{kg} \cdot \mathrm{m}^{-2}\right)$ & $24.7 \pm 3.9$ & $23.3 \pm 2.7$ & $26.5 \pm 3.8$ & $24.8 \pm 3.3$ & $<0.001$ & $<0.001$ \\
\hline Age(years) & $39 \pm 12$ & $37 \pm 11$ & $40 \pm 14$ & $39 \pm 15$ & 0.253 & 0.158 \\
\hline Sex(Male count $(\%))$ & $83(40)$ & $84(63)$ & $61(73)$ & $67(72)$ & 0.001 & $<0.001$ \\
\hline Born 'here'(count $(\%)$ ) & $171(85)$ & $107(82)$ & $65(78)$ & $74(82)$ & 0.873 & 0.383 \\
\hline
\end{tabular}

Values are mean \pm SD unless specified. Age is participant's age at recruitment (CON) or age at injury (TEN). Born 'here' is the number and proportion of participants born in Australasia (AUS) or Southern Africa (SA). P-values are for the difference between countries and between diagnostic groups respectively, adjusted for each other.

The two populations were therefore summarised separately. All genotype distributions were in HWE except at the rs28494505 locus that deviated significantly in the AUS control group $(\mathrm{P}=0.043)$. It was, however, noted that a lower genotype call rate was observed for this variant in the AUS samples. There were no significant genotype effects on age, weight, height, BMI or sex after adjusting for possible confounders (Table III). After adjusting for the potential confounder's age, sex, country grouping and country of birth, there were no significant differences in either the genotype or allele frequency distributions between the control and tendinopathy groups. 


\begin{tabular}{|c|c|c|c|c|c|c|}
\hline & \multicolumn{2}{|c|}{$\mathrm{CON}$} & \multicolumn{2}{|c|}{ TEN } & \multicolumn{2}{|c|}{$P$-values } \\
\hline & AUS & SA & AUS & SA & Country & Group \\
\hline \multicolumn{7}{|c|}{$\begin{array}{l}\text { COMP: } \\
\text { rs28494505 }\end{array}$} \\
\hline$N$ & 165 & 131 & 62 & 94 & & \\
\hline $\mathrm{A} / \mathrm{A}$ & 0.80 & 0.54 & 0.68 & 0.62 & $<0.001$ & 0.994 \\
\hline $\mathrm{A} / \mathrm{G}$ & 0.17 & 0.43 & 0.26 & 0.36 & & \\
\hline G/G & 0.03 & 0.03 & 0.06 & 0.02 & & \\
\hline G & 0.12 & 0.24 & 0.19 & 0.2 & $<0.001$ & 0.919 \\
\hline $\begin{array}{l}\text { HWE } \\
\text { rs } 7300\end{array}$ & \multicolumn{3}{|c|}{ rs730079 } & 0.345 & & \\
\hline$N$ & 205 & 131 & 83 & 93 & & \\
\hline $\mathrm{G} / \mathrm{G}$ & 0.34 & 0.38 & 0.39 & 0.35 & 0.687 & 0.727 \\
\hline $\mathrm{G} / \mathrm{C}$ & 0.50 & 0.43 & 0.45 & 0.47 & & \\
\hline $\mathrm{C} / \mathrm{C}$ & 0.16 & 0.19 & 0.17 & 0.17 & & \\
\hline $\mathrm{C}$ & 0.41 & 0.40 & 0.39 & 0.41 & 0.978 & 0.455 \\
\hline HWE & 0.773 & 0.206 & 0.644 & 0.832 & & \\
\hline \multirow{2}{*}{\multicolumn{7}{|c|}{$\begin{array}{l}\text { THBS2: } \\
\text { rs9505888 }\end{array}$}} \\
\hline & & & & & & \\
\hline$N$ & 185 & 130 & 75 & 93 & & \\
\hline $\mathrm{G} / \mathrm{G}$ & 0.26 & 0.33 & 0.32 & 0.32 & 0.602 & 0.244 \\
\hline G/A & 0.55 & 0.52 & 0.44 & 0.47 & & \\
\hline $\mathrm{A} / \mathrm{A}$ & 0.19 & 0.15 & 0.24 & 0.20 & & \\
\hline A & 0.46 & 0.41 & 0.46 & 0.44 & 0.315 & 0.533 \\
\hline $\begin{array}{l}\text { HWE } \\
\text { s } 6422\end{array}$ & 0.236 & 0.467 & 0.354 & 0.679 & & \\
\hline $\begin{array}{l}\text { rs6422 } \\
N\end{array}$ & 200 & 130 & 82 & 93 & \multicolumn{2}{|c|}{ rs6422747 } \\
\hline $\mathrm{A} / \mathrm{A}$ & 0.42 & 0.34 & 0.34 & 0.35 & 0.024 & 0.645 \\
\hline $\mathrm{A} / \mathrm{G}$ & 0.51 & 0.43 & 0.50 & 0.47 & & \\
\hline $\mathrm{G} / \mathrm{G}$ & 0.08 & 0.23 & 0.16 & 0.17 & & \\
\hline G & 0.33 & 0.45 & 0.41 & 0.41 & 0.055 & 0.480 \\
\hline $\begin{array}{l}\text { HWE } \\
\text { rs } 9283\end{array}$ & 0.058 & 0.156 & 0.823 & 0.832 & & \\
\hline Typed & 203 & 130 & 79 & 93 & & \\
\hline $\mathrm{A} / \mathrm{A}$ & 0.28 & 0.28 & 0.25 & 0.25 & 0.965 & 0.604 \\
\hline $\mathrm{A} / \mathrm{G}$ & 0.43 & 0.48 & 0.53 & 0.46 & & \\
\hline $\mathrm{G} / \mathrm{G}$ & 0.29 & 0.23 & 0.22 & 0.29 & & \\
\hline G & 0.50 & 0.47 & 0.48 & 0.52 & 0.889 & 0.632 \\
\hline HWE & 0.068 & 0.728 & 0.655 & 0.533 & & \\
\hline
\end{tabular}

P-values are for the difference between countries and between diagnostic groups respectively, adjusted for each other, age at injury/ recruitment, sex and whether or not a person was investigated in his/her country of birth. The genotype $P$-value is calculated using a 2-degrees of freedom test, with genotypes as categories and the allelic $P$-value is calculated using an additive allelic model. HWE gives exact $P$-values from tests of Hardy-Weinberg equilibrium. $N$ is the number of samples genotyped. Bold $P$-values are $<0.05$.

\section{Discussion}

Theprimary finding of this study is that there was no association of the selected genetic variants within the COMP and THBS2 candidate genes with Achilles tendinopathy in the two populations studied. This study was only sufficiently powered to detect large effects on risk of developing Achilles tendinopathy (odds ratio (OR) >2) (Gauderman, 2002), and wasthereforeunlikely to detect any risk variant with a small effect. However, it should be noted that there was no tendency towards association with Achilles tendinopathyfor any of the variants investigated. Although we cannot exclude thepossibility that other variants within these genesare associated with Achilles tendinopathy, all the SNPsinvestigatedinthisstudy were identified as Tag SNPs and it is, therefore, unlikely that any SNPs tightly linked to these would show a significant effect on risk of Achilles tendinopathy. Both THBS2 $(38,3 \mathrm{~kb})$ and $C O M P(8,5 \mathrm{~kb})$ are small genes and the Tag SNPs selected span 11,6kb and 9,9kb respectively, therefore giving moderate coverage of both genes. However, it still remains possible that other rare or common sequence variants within COMP and THBS2 may be associated withthe riskof Achillestendinopathy. 
Table III. Genotype effects of polymorphisms investigated within the COMP and THBS2 genes on physiological characteristics of participants.

\begin{tabular}{|c|c|c|c|c|c|}
\hline POLYMORPHISM & AGE (years) & SEX (\% male) & HEIGHT (cm) & WEIGHT (kg) & BMI $\left(\mathrm{kg} \cdot \mathrm{m}^{-2}\right)$ \\
\hline \multicolumn{6}{|l|}{ Genotype } \\
\hline rs 28494505 & 0.092 & 0.633 & 0.680 & 0.935 & 0.952 \\
\hline rs730079 & 0.262 & 0.551 & 0.997 & 0.523 & 0.353 \\
\hline rs9505888 & 0.392 & 0.129 & 0.474 & 0.390 & 0.116 \\
\hline rs6422747 & 0.070 & 0.118 & 0.342 & 0.224 & 0.734 \\
\hline rs9283850 & 0.994 & 0.102 & 0.672 & 0.819 & 0.481 \\
\hline
\end{tabular}

Values are $P$-values for genetic association, adjusted for TEN group, age at injury/recruitment (except age), sex (except sex), country and whether or not a person was investigated in his/her country of birth. The genotype $P$-value is calculated using a 2-degrees of freedom test, with genotypes as categories. Bold $P$-values are $<0.05$.

Previous work in this area has shown that genetic variants in genes encoding structural components of the collagen fibril often have large effects on risk of developing Achilles tendinopathy (OR>2) (Mokone et al., 2005; Mokone et al., 2006; Raleigh et al., 2009). Furthermore, rare mutations within genes encoding these structural components cause a range of severe disorders of connective tissue including pseudoachondroplasia, multiple epiphyseal dysplasia, osteogenesis imperfecta and Ehlers-Danlos syndrome (Hecht et al., 2005; Ikegawa et al., 1998; Malfait et al., 2005; Michalickova, Susic, Willing, Wenstrup, \& Cole, 1998; Pollitt et al., 2006; Smith, Schwarze, Goldstein, \& Byers, 1997). Based on these observations it has been suggested that there is limited redundancy within the biological mechanisms leading to collagen fibrillogenesis, and that common variants in the associated genes may have large effects on the risk of developing mild connective tissue pathology, such as Achilles tendinopathy (Ribbans \& Collins, 2013).

The thrombospondins are calcium binding glycoproteins that can be divided into two subfamilies with distinct biological roles (Adams \& Lawler, 2004; Bornstein et al., 2004). However, the carboxy terminal signature domain of all thrombospondins, which contains the EGF-like repeats, type III calcium binding repeats and a carboxy terminal lectin-like globule, is highly conserved between the five members of this protein family (Adams \& Lawler, 2004; Carlson et al., 2008). Thrombospondin-1 and thrombospondin-2 are matricellular proteins that form homotrimers and modulate cell functions and cell-matrix interactions (Bornstein et al., 2004), while thrombospondin-3,-4 and -5 are structural proteins of the extracellular matrix and form homopentamers (Adams \& Lawler, 2004; Bornstein et al., 2000; Bornstein et al., 2004). Investigation of thrombospondin-2 null mice has implicated this protein in the regulation of collagen fibrillogenesis and fibril diameter, possibly through its regulation of ambient matrix metalloproteinase-2 levels (Bornstein et al., 2000; Bornstein et al., 2004; Kyriakides et al., 1998). Cartilage oligomeric matrix protein is expressed in bovine and equine tendons, particularly in growing tendons and in response to mechanical load (DiCesare, Hauser, Lehman, Pasumarti, \& Paulsson, 1994; Smith, Birch, Goodman, Heinegard, \& Goodship, 2002; Smith, Zunino, Webbon, \& Heinegard, 1997). Recent investigation has identified a mechano-responsive element in the $3 \mathrm{~kb}$ proximal promoter of the human COMP gene (Amanatullah et al., 2012). In numerous studies of equine tendons, Smith et al. (Smith, Birch, et al., 2002; Smith, Gerard, et al., 2002; Smith, Zunino et al., 1997) have shown that cartilage oligomeric matrix protein levels are correlated to ultimate tensile stress and stiffness of tendon tissue and suggest that the appropriate expression of cartilage oligomeric matrix protein is necessary for the formation of a functional ECM 
and the structural integrity of tendons. Additionally, serum cartilage oligomeric matrix protein has been inversely associated with joint hypermobility (Chen et al., 2008), a risk factor for Achilles tendinopathy (Collins, Mokone, September, van der Merwe, \& Schwellnus, 2009). There is also evidence to suggest that variations within the signature domain of the COMP gene alter protein structure and folding, and disrupt calcium binding (Chen, Deere, Hecht, \& Lawler, 2000; Hecht et al., 2005; Hou, Putkey, \& Hecht, 2000; Kvansakul, Adams, \& Hohenester, 2004; Maddox, Mokashi, Keene, \& Bachinger, 2000). It is therefore possible that sequence variants that have even a minor effect on transcription, translation or protein structure and function will result in at least a mild inherited clinical dysplasia. Taking into account the high sequence conservation of both the $C O M P$ and $T H B S 2$ genes between species, it remains possible that rare sequence variants (minor allele frequency $0.1-3.0 \%$ ) within these genes might be associated with a large effect on the risk of Achilles tendinopathy (Bodmer \& Bonilla, 2008; Ovcharenko, Nobrega, Loots, \& Stubbs, 2004). Such rare variants often have a larger effect on risk as well as greater penetrance, making them good targets for prophylactic treatments (Bodmer \& Bonilla, 2008). For example, the rare TT genotype $(<5 \%$ in Caucasian

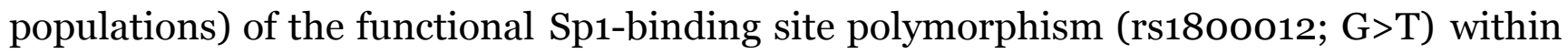
intron 1 of the COL1A1 gene is associated with reduced risk of acute soft tissue ruptures (Collins, Posthumus, \& Schwellnus, 2009; Khoschnau et al., 2008; Posthumus et al., 2009). Associations of common multifactorial diseases with rare variants are unlikely to be found by either genome-wide association studies or casecontrol association studies such as the current study, and further work would therefore be necessary to test this hypothesis (Bodmer \& Bonilla, 2008).

\section{Strengths and limitations}

A limitation to this study is that the tendinopathy participants were significantly heavier than the control participants at the time of recruitment. Although the tendinopathy participant's weight at the time of injury was not determined, several participants reported an increase in weight after injury due to inactivity. In addition, this difference may be explained by the higher proportion of males in the tendinopathy groups as the difference was much less pronounced after adjusting for country, sex and age. Another limitation is that, due to a low sample size, this study was only sufficiently powered to detect large effects on risk of AT (OR>2.0). The strength of this study lays in the hypothesis-driven selection of the candidate genes and variants investigated, and the stringent selection of homogenous tendinopathy participants.

\section{Conclusions}

In conclusion, this study did not identify an association between the common sequence variants investigated and increased risk of Achilles tendinopathy.

\section{Acknowledgements}

This research was supported by funds received from the National Research Foundation (NRF), the Medical Research Council (MRC) of South Africa, The University of Cape Town and Discovery Health. We thank Dr G.G. Mokone for 
recruiting the SA participants and Professor M.P. Schwellnus for the clinical diagnoses of the SA participants. 


\section{References}

Adams, J.C. \& Lawler, J. (2004). The thrombospondins. The InternationalJournal of Biochemistry \& Cell Biology, 36, 961-968.

Amanatullah, D.F., Lu, J., Hecht, J., Posey, K., Yik, J., Di Cesare, P.E. et al. (2012). Identification of a $3 \mathrm{Kbp}$ mechanoresponsive promoter region in the human cartilage oligomeric matrix protein gene. Tissue Engineering Part A, 18, 18821889.

Bodmer, W. \& Bonilla, C. (2008). Common and rare variants in multifactorial susceptibility to common diseases. Nature Genetics, 40, 695-701.

Bornstein, P., Agah, A., \& Kyriakides, T.R. (2004). The role of thrombospondins 1 and 2 in the regulation of cell-matrix interactions, collagen fibril formation, and the response to injury. International Journal of Biochemistry \& Cell Biology, 36, $1115-1125$.

Bornstein, P., Armstrong, L.C., Hankenson, K.D., Kyriakides, T. R., \& Yang, Z.T. (2000). Thrombospondin 2, a matricellular protein with diverse functions. Matrix Biology, 19, 557-568.

Carlson, C.B., Lawler, J., \& Mosher, D.F. (2008). Structure of thrombospondins. Cellular and Molecular Life Sciences, 65, 672-686.

Chen, H., Deere, M., Hecht, J.T., \& Lawler, J. (2000). Cartilage oligomeric matrix protein is a calcium-binding protein, and a mutation in its type 3 repeats causes conformational changes. Journal of Biological Chemistry, 275, 2653826544 .

Chen, H.C., Shah, S.H., Li, Y.J., Stabler, T.V., Jordan, J.M., \& Kraus, V.B. (2008). Inverse association of general joint hypermobility with hand and knee osteoarthritis and serum cartilage oligomeric matrix protein levels. Arthritis \& Rheumatism, 58, 3854-3864.

Collins, M., Mokone, G.G., September, A.V., van der Merwe, L., \& Schwellnus, M.P. (2009). The COL5A1 genotype is associated with range of motion measurements. Scandinavian Journal of Medicine \& Science in Sports, 19, 803810.

Collins, M., Posthumus, M., \& Schwellnus, M.P. (2009). The COL1A1 gene and acute soft tissue ruptures. British Journal of Sports Medicine, 44, 1063-1064.

Collins, M. \& Raleigh, S. M. (2009). Genetic risk factors for musculoskeletal soft tissue injuries. Medicine \& Sport Science, 54, 136-149.

de Jonge, S., van den, B.C., de Vos, R.J., van der Heide, H.J., Weir, A., Verhaar, J.A. et al. (2011). Incidence of midportion Achilles tendinopathy in the general population. British Journal of Sports Medicine, 45, 1026-1028.

Del Buono, A., Chan, O., \& Maffulli, N. (2013). Achilles tendon: Functional anatomy and novel emerging models of imaging classification. International Orthopaedics, $37,715-721$.

Delot, E., King, L.M., Briggs, M.D., Wilcox, W.R., \& Cohn, D. H. (1999). Trinucleotide expansion mutations in the cartilage oligomeric matrix protein (COMP) gene. Human Molecular Genetics, 8, 123-128. 
DiCesare, P., Hauser, N., Lehman, D., Pasumarti, S., \& Paulsson, M. (1994). Cartilage oligomeric matrix protein (COMP) is an abundant component of tendon. FEBS Letters, 354, 237-240.

Gauderman, W.J. (2002). Sample size requirements for matched case-control studies of gene-environment interaction. Statistics in Medicine, 21, 35-50.

Hecht, J.T., Hayes, E., Haynes, R., \& Cole, W.G. (2005). COMP mutations, chondrocyte function and cartilage matrix. Matrix Biology, 23, 525-533.

Hirose, Y., Chiba, K., Karasugi, T., Nakajima, M., Kawaguchi, Y., Mikami, Y. et al. (2008). A functional polymorphism in THBS2 that affects alternative splicing and MMP binding is associated with lumbar-disc herniation. American Journal of Human Genetics, 82, 1122-1129.

Hou, J., Putkey, J.A., \& Hecht, J.T. (2000). Delta 469 mutation in the type 3 repeat calcium binding domain of cartilage oligomeric matrix protein (COMP) disrupts calcium binding. Cell Calcium, 27, 309-314.

Ikegawa, S., Ohashi, H., Nishimura, G., Kim, K.C., Sannohe, A., Kimizuka, M. et al. (1998). Novel and recurrent COMP (cartilage oligomeric matrix protein) mutations in pseudoachondroplasia and multiple epiphyseal dysplasia. Human Genetics, 103, 633-638.

Jarvinen, M., Jozsa, L., Kannus, P., Jarvinen, T.L., Kvist, M., \& Leadbetter, W. (1997). Histopathological findings in chronic tendon disorders. Scandinavian Journal of Medicine \& Science in Sports, 7, 86-95.

Jarvinen, T.A., Kannus, P., Paavola, M., Jarvinen, T.L., Jozsa, L., \& Jarvinen, M. (2001). Achilles tendon injuries. Current Opinion in Rheumatology, 13, 150-155.

Kader, D., Saxena, A., Movin, T., \& Maffulli, N. (2002). Achilles tendinopathy: Some aspects of basic science and clinical management. British Journal of Sports Medicine, 36, 239-249.

Kannus, P. (1997). Etiology and pathophysiology of chronic tendon disorders in sports. Scandinavian Journal of Medicine \& Science in Sports, 7, 78-85.

Kannus, P. \& Natri, A. (1997). Etiology and pathophysiology of tendon ruptures in sports. Scandinavian Journal of Medicine \& Science in Sports, 7, 107-112.

Khan, K.M., Cook, J.L., Kannus, P., Maffulli, N., \& Bonar, S.F. (2002). Time to abandon the 'tendinitis' myth. British Medical Journal, 324, 626-627.

Khoschnau, S., Melhus, H., Jacobson, A., Rahme, H., Bengtsson, H., Ribom, E. et al. (2008). Type I collagen alpha1 Sp1 polymorphism and the risk of cruciate ligament ruptures or shoulder dislocations. American Journal of Sports Medicine, 36, 2432-2436.

Kujala, U.M., Sarna, S., \& Kaprio, J. (2005). Cumulative incidence of Achilles tendon rupture and tendinopathy in male former elite athletes. Clinical Journal of Sport Medicine, 15, 133-135.

Kvansakul, M., Adams, J.C., \& Hohenester, E. (2004). Structure of a thrombospondin C-terminal fragment reveals a novel calcium core in the type 3 repeats. EMBO Journal, 23, 1223- 1233.

Kyriakides, T.R., Zhu, Y.H., Smith, L.T., Bain, S.D., Yang, Z., Lin, M.T. et al. (1998). Mice that lack thrombospondin 2 display connective tissue

\section{http://repository.uwc.ac.za}


abnormalities that are associated with disordered collagen fibrillogenesis, an increased vascular density, and a bleeding diathesis. Journal of Cell Biology, $140,419-430$.

Lahiri, K. \& Nurnberger, J.I. (1991). A rapid non-enzymatic method for the preparation of HMW DNA from blood for RFLP studies. Nucleic Acids Research, 19, 5444.

Maddox, B.K., Mokashi, A., Keene, D.R., \& Bachinger, H.P. (2000). A cartilage oligomeric matrix protein mutation associated with pseudoachondroplasia changes the structural and functional properties of the type 3 domain. Journal of Biological Chemistry, 275, 11412-11417.

Maffulli, N., Khan, K.M., \& Puddu, G. (1998). Overuse tendon conditions: Time to change a confusing terminology. Arthroscopy, 14, 840-843.

Malfait, F., Coucke, P., Symoens, S., Loeys, B., Nuytinck, L., \& De Paepe, A. (2005). The molecular basis of classic Ehlers-Danlos syndrome: A comprehensive study of biochemical and molecular findings in 48 unrelated patients. Human Mutation, 25, 28-37.

Michalickova, K., Susic, M., Willing, M.C., Wenstrup, R.J., \& Cole, W.G. (1998). Mutations of the alpha2(V) chain of type $\mathrm{V}$ collagen impair matrix assembly and produce ehlers-danlos syndrome type I. Human Molecular Genetics, 7, 249-255.

Mokone, G.C., Gajjar, M., September, A.V., Schwellnus, M.P., Greenburg, J., Noakes, T.D. et al. (2005). The Guanine-Thymine dinucleotide repeat polymorphism within the Tenascin-C gene is associated with Achilles tendon injuries. American Journal of Sports Medicine, 33, 1016-1021.

Mokone, G.G., Schwellnus, M.P., Noakes, T.D., \& Collins, M. (2006). The COL5A1 gene and Achilles tendon pathology. Scandinavian Journal of Medicine \& Science in Sports, 16, 19-26. Nell, E.M., van der Merwe, L., Cook, J., Handley, C.J., Collins, M., \& September, A.V. (2012). The apoptosis pathway and the genetic predisposition to Achilles tendinopathy. Journal of Orthopaedic Research, 30, 1719-1724.

Ovcharenko, I., Nobrega, M.A., Loots, G.G., \& Stubbs, L. (2004). ECR Browser: A tool for visualizing and accessing data from comparisons of multiple vertebrate genomes. Nucleic Acids Research, 32, W280-W286.

Pollitt, R., McMahon, R., Nunn, J., Bamford, R., Afifi, A., Bishop, N. et al. (2006). Mutation analysis of COL1A1 and COL1A2 in patients diagnosed with osteogenesis imperfecta type I-IV. Human Mutation, 27, 716.

Posey, K.L., Yang, Y., Veerisetty, A.C., Sharan, S.K., \& Hecht, J. T. (2008). Model systems for studying skeletal dysplasias caused by TSP-5/COMP mutations. Cellular \& Molecular Life Sciences, 65, 687-699.

Posthumus, M., Collins, M., Cook, J., Handley, C.J., Ribbans, W. J., Smith, R.K.W. et al. (2010). Components of the transforming growth factor-beta family and the pathogenesis of human Achilles tendon pathology-a genetic association study. Rheumatology, 49, 2090-2097.

Posthumus, M., September, A.V., Keegan, M., O'Cuinneagain, D., van der Merwe, W., Schwellnus, M.P. et al. (2009). Genetic risk factors for anterior cruciate 
ligament ruptures: COL1A1 gene variant. British Journal of Sports Medicine, 43, $352-356$.

R Development Core Team (2010). R: A language and environment for statistical computing. R Foundation for Statistical Computing, www.r-project.org.

Raleigh, S.M., van der Merwe, L., Ribbans, W.J., Smith, R.K., Schwellnus, M.P., \& Collins, M. (2009). Variants within the MMP3 gene are associated with Achilles tendinopathy: Possible interaction with the COL5A1 gene. British Journal of Sports Medicine, 43, 514-520.

Rees, S.G., Dent, C.M., \& Caterson, B. (2009). Metabolism of proteoglycans in tendon. Scandinavian Journal of Medicine \& Science in Sports, 19, 470-478.

Ribbans, W.J. \& Collins, M. (2013). Achilles tendon problems - do our genes contribute? Journal of Bone and Joint Surgery - British Volume, 95-B, 305-313.

Rosenberg, K., Olsson, H., Morgelin, M., \& Heinegard, D. (1998). Cartilage oligomeric matrix protein shows high affinity zinc-dependent interaction with triple helical collagen. Journal of Biological Chemistry, 273, 20397-20403.

Saunders, C.J., van der Merwe, L., Posthumus, M., Cook, J., Handley, C.J., Collins, M. et al. (2013). Investigation of variants within the COL27A1 and TNC genes and Achilles tendinopathy in two populations. Journal of Orthopaedic Research, 31, 632-637.

Schepsis, A.A., Jones, H., \& Haas, A.L. (2002). Achilles tendon disorders in athletes. American Journal of Sports Medicine, 30, 287-305.

September, A.V., Cook, J., Handley, C.J., van der Merwe, L., Schwellnus, M.P., \& Collins, M. (2009). Variants within the COL5A1 gene are associated with Achilles tendinopathy in two populations. British Journal of Sports Medicine, 43, $357-365$.

September, A.V., Mokone, G.G., Schwellnus, M.P., \& Collins, M. (2006). Genetic risk factors for Achilles tendon injuries. International SportMed Journal, 7, 201215 .

September, A.V., Nell, E.M., O'Connell, K., Cook, J., Handley, C.J., van der Merwe, L. et al. (2011). A pathway-based approach investigating the genes encoding interleukin-1beta, interleukin-6 and the interleukin-1 receptor antagonist provides new insight into the genetic susceptibility of Achilles tendinopathy. British Journal of Sports Medicine, 45, 1040-1047.

Smith, L.T., Schwarze, U., Goldstein, J., \& Byers, P.H. (1997). Mutations in the COL3A1 gene result in the Ehlers-Danlos syndrome type IV and alterations in the size and distribution of the major collagen fibrils of the dermis. Journal of Investigative Dermatology, 108, 241-247.

Smith, R.K., Birch, H.L., Goodman, S., Heinegard, D., \& Goodship, A.E. (2002). The influence of ageing and exercise on tendon growth and degeneration hypotheses for the initiation and prevention of strain-induced tendinopathies. Comparative Biochemistry \& Physiology Part A: Molecular \& Integrative Physiology, 133, 1039-1050.

Smith, R.K., Gerard, M., Dowling, B., Dart, A.J., Birch, H.L., \& Goodship, A.E. (2002). Correlation of cartilage oligomeric matrix protein (COMP) levels in equine 
tendon with mechanical properties: A proposed role for COMP in determining function-specific mechanical characteristics of locomotor tendons. Equine Veterinary Journal Supplement, 241-244.

Smith, R.K., Zunino, L., Webbon, P.M., \& Heinegard, D. (1997). The distribution of cartilage oligomeric matrix protein (COMP) in tendon and its variation with tendon site, age and load. Matrix Biology, 16, 255-271.

Sodersten, F., Hultenby, K., Heinegard, D., Johnston, C., \& Ekman, S. (2013). Immunolocalization of collagens (I and III) and cartilage oligomeric matrix protein (COMP) in the normal and injured equine superficial digital flexor tendon. Connective Tissue Research, 54, 62-69.

Valdes, A.M., Loughlin, J., Oene, M.V., Chapman, K., Surdulescu, G.L., Doherty, M. et al. (2007). Sex and ethnic differences in the association of ASPN, CALM1, COL2A1, COMP, and FRZB with genetic susceptibility to osteoarthritis of the knee. Arthritis \& Rheumatism, 56, 137-146.

Warnes, G., Gorjanc, G., Leisch, F., \& others (2011). Genetics: A package for population genetics (Version Version 1.3.6), http:// cran.r-project.org/package=genetics.

$\mathrm{Xu}$, Y. \& Murrell, G.A. (2008). The basic science of tendinopathy. Clinical Orthopaedics \& Related Research, 466, 1528-1538. 